\title{
Analysis of Garlic Cultivars Using Head Space Solid Phase Microextrac- tion/Gas Chromatography/Mass Spectroscopy
}

\author{
Jessica G. Clemente ${ }^{1}$, Jack D. Williams ${ }^{1 *}$, Marlene Cross ${ }^{2}$ and Candace C. Chambers ${ }^{3}$ \\ ${ }^{1}$ Department of Chemistry and Biochemistry, Mercyhurst University, Erie PA 16546 \\ ${ }^{2}$ Department of Biology, Mercyhurst University, Erie PA 16546 \\ ${ }^{3}$ College of Arts and Sciences, Maryville University, St. Louis MO 63141
}

\begin{abstract}
Garlic has been widely used throughout history as a food additive for both its flavor and medicinal effects. The actual sulfide compounds found in garlic as well as the potential health benefits associated with garlic have been extensively studied. It has been shown that garlic preparation, growing conditions and cooking techniques, have a profound effect on the compounds present and the medicinal qualities afforded. Considering the number of garlic cultivars available and the large focus on growing food organically, differentiation between different garlic cultivars would be useful. Using SPME and GC-MS the sulfur compounds present in a variety of garlic types where identified and quantified. Principal component analysis enabled the differentiation of the cultivars studied and in one case the differentiation of Organic and Non-Organically grown soft neck garlic.
\end{abstract}

Keywords: Allium sativum, Garlic, Organic, Principal Component Analysis (PCA), Solid Phase Microextraction Gas Chromatography Mass Spectroscopy (SPME/GC/MS), Cultivar.

\section{INTRODUCTION}

Garlic (Allium sativum) has been utilized throughout history, serving both as a food supplement as well as a treatment for many ailments. The earliest records of garlic use date back to around 3,000 BC, when the father of Ayurvedic medicine, Charak, stated that garlic helped maintain fluidity of blood and strengthened the heart [1]. Recent research has revealed many different benefits of garlic on human health, including anticarcinogenic, antifungal, and antibacterial properties [2]. In animal studies garlic was found to modulate the activity of proteins that are linked with diabetes and obesity-related cardiac disorders [3].

It is these benefits that have driven the extensive research on the volatile components of garlic to determine which compounds are responsible for the health benefits. Many specific chemicals in garlic have been directly linked to having an inhibitory effect on chemical carcinogenesis [4]. However a problem faced when working with garlic is the instability of the sulfur-containing compounds. The amino acid alliin is present in whole garlic cloves.

When the clove is crushed, the enzyme alliinase (Scheme 1) is activated and breaks down alliin into allicin and other allyl thiosulfinates [5]. At least 35 different compounds have been identified in garlic [6]. These sulfur-containing compounds have been the focus of the many quantitative and qualitative studies on garlic and related species [7].

*Address correspondence to this author at the Department of Chemistry and Biochemistry, Mercyhurst University, Erie PA 16546; Tel: (814) 824-2386; Fax: (814) 824-2188; E-mail: jwilliams@mercyhurst.edu

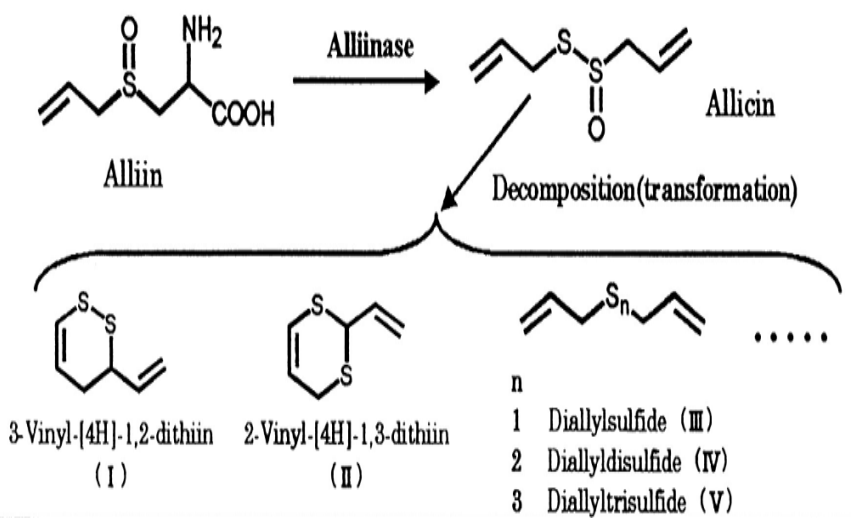

Scheme 1. Breakdown of the amino acid alliin into allicin by the enzyme alliinase upon the crushing of a garlic clove. Allicin subsequently decomposes into different sulfide compounds, the main components of garlic [16].

The allicins and sulfide compounds in Allium plants, notably garlic, onion (A. серa), and scallion (A. ascalonicum), are presumed to be responsible for their distinct flavors and aromas [8]. Studies have shown the chemical distinctions between the species in the amount and types of compounds present [7, 8]. Through Principal Component Analysis (PCA), differentiating garlic has been performed based on diversity in garlic genes [9], the country of origin [10], the type of food preparation technique [11], and morphological characteristics of garlic [12]. To our knowledge however, there is no published data on the use of PCA to separate garlic cultivars. 
The means by which garlic is grown and later prepared may also have a significant effect on the sulfide compounds present and hence on the benefits available to the consumer. Garlic grown in a cooler climate has a different distribution of compounds versus garlic grown in a warmer climate [13]. The way garlic is prepared, whether it be deep-fried, microwave-heated, oven-baked, etc., also has an effect on its chemical composition [14]. The health benefits can also vary with preparation. Freshly cut garlic has been found to have greater cardio protective effects, compared to processed garlic [3].

\section{MATERIALS}

\subsection{Garlic Samples}

Non-Organic (Soft Neck, Spice World Inc. Orlando FL), Organic (Soft Neck, Spice World Inc. Orlando FL) and Elephant Garlic (A. ampeloprasum) (Spice World Inc, Orlando FL) where purchased from Wegmans Supermarket (Erie, PA, USA). Elephant garlic is not a true garlic, but is more closely related to leeks. The two other garlic cultivars used in this study were 'Shvelisi' and 'Dailey'. Shvelisi is a purple stripe cultivar also known as 'Chesnok Red' in the trade. Dailey is a popular locally adapted cultivar that is most likely a Rocambole type. These two cultivars were grown in an organic garden in Erie, PA., and harvested in July, 2010.

\subsection{Instrumentation}

Analysis of garlic samples was performed using an Agilent Technologies 7890A Gas Chromatograph equipped with a 5975C Mass Selector and Gerstel MPS2 (Multi- Purpose Autosampler). The column used in the GC was a DB624, $30 \mathrm{~m} \times 0.250 \mathrm{~mm} \times 1.4 \mu \mathrm{m}$ with a carrier gas of Helium. MSD ChemStation Software (Version E.02.01.1177) was used for peak analysis of the volatile components. The Unscrambler X (CAMO Software) was used for PCA analysis.

\section{METHODOLOGY}

\subsection{Sample Preparation}

All garlic samples were prepared in the same manner. The garlic bulb was broken apart into individual cloves, then the cloves were peeled so no outer covering remained. The ends of the cloves were cut off, then the remaining garlic was chopped into similar-sized pieces using a 3 in. kitchen knife (EKO Stainless, USA). Exactly $2.0 \mathrm{~g}$ of the garlic was measured on a balance (Adventurer Pro, model AV114, Ohaus). Three samples were collected from three separate bulbs of each of the garlic cultivars.

\subsection{Sample Storage}

Garlic samples were immediately placed into $20 \mathrm{~mL}$ clear screw cap vials (Gerstel Inc.), weighed and the vials sealed with magnetic screw caps lined with blue silicone/PTFE septa (Gerstel Inc.). Experimental results showed that leaving garlic uncovered over any period of time significantly reduced the amount of volatiles present.

\subsection{SPME Technique and Instrument Parameters}

Garlic sample volatiles were extracted for $3.0 \mathrm{~min}$ at room temperature using Solid Phase Microextraaction (SPME). This technique is ideally suited for solid samples [15]. A Carboxen Polydimethylsiloxane (CAR/PDMS) SPME fiber was chosen for optimal volatile extraction, based on published research $[17,18]$. Desorption (5.0 min), took place in the GC injection port operating in split mode (20:1) at a temperature of $250{ }^{\circ} \mathrm{C}$. The carrier gas (Helium) flow rate was set at $1 \mathrm{~mL} / \mathrm{min}$ with a temperature program of $50{ }^{\circ} \mathrm{C}$ for $3 \mathrm{~min}$, then $5^{\circ} \mathrm{C} / \mathrm{min}$ to $210^{\circ} \mathrm{C}$ for a total run time of $35.0 \mathrm{~min}$. Scan parameters were set from 15.0 to 240.0 amu for the Mass Spectrometer analysis.

Absorption time was optimized as shown in Fig. (1). using a sample of nonorganic garlic. A three minute extraction time gave maximum total volatiles.

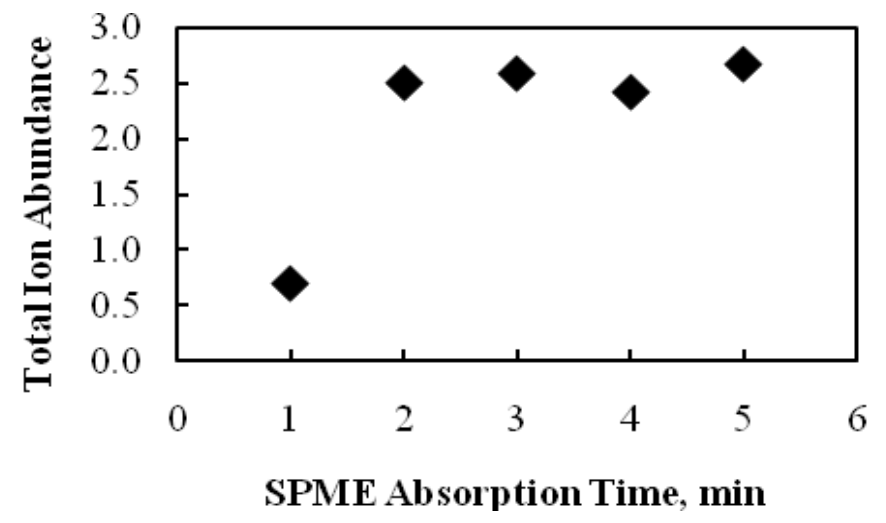

Fig. (1). Total volatiles extracted (area from total ion chromatogram $\mathrm{x} 10^{9}$ ) versus SPME extraction time for a two gram sample of nonorganic garlic.

Fiber desorption time was set to five minutes. Using this desorption time no analyte carryover could be detected in a blank sample analyzed after prior absorption of garlic analytes followed by GCMS analysis.

\subsection{Principal Component Analysis Optimization}

A consistent, reproducible method for sample preparation and volatile extraction that enabled a successful PCA separation was obtained by using SPME extraction and a 7890A Gas Chromatogram equipped with an Autosampler. When the five different garlic samples (see "Garlic Samples for SPME and PCA Analysis") were initially analyzed using PCA, no separation was seen. Upon further examination of the chromatograms, it was determined that the garlic samples were being analyzed too quickly after preparation. Compound levels where changing during the analysis, limiting the reproducibility of the samples run in triplicate. Separation through the PCA was not seen using these samples. Chromatograms showing this progression are shown in Fig (2).

To solve this problem the garlic samples were allowed to sit in a sealed vial for one, seven, and fourteen days, to allow volatile composition to stabilize. Three separate trials for each time interval were performed to optimize separation when analyzed with PCA. The 14 day samples showed the best separation in the PCA analysis. 


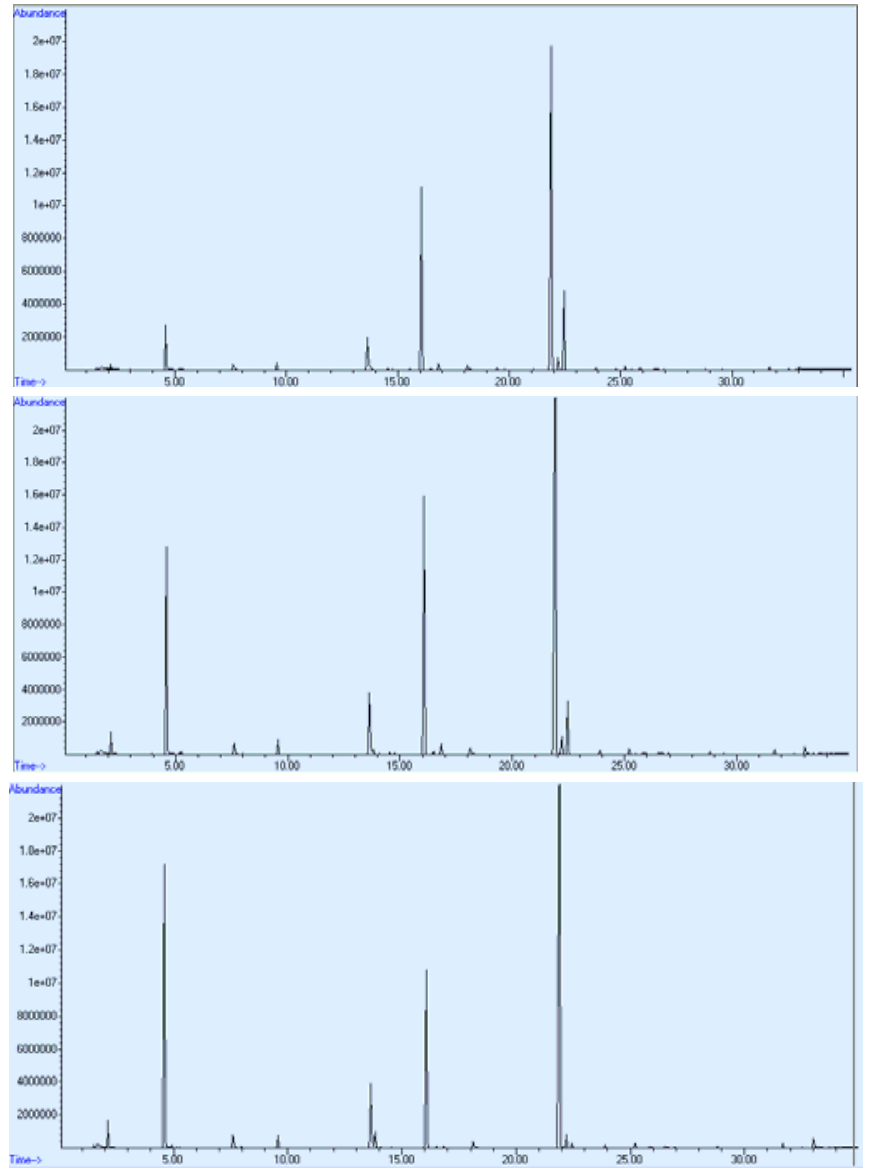

Fig. (2). Three chromatograms of the three freshly cut sample of Shvelisi garlic. Top - analysis within 5 min. Middle - after standing for $35.0 \mathrm{~min}$. Bottom - after standing for $70.0 \mathrm{~min}$.
The change in volatile composition of fresh cut garlic is not surprising considering the process by which garlic sulfur compounds are formed [5].

\section{RESULTS AND DISCUSSION}

Table 1 shows quantitative differences between the five different garlic samples. The total ion chromatograms (total of the relative abundances) for each of the eight volatiles measured is listed along with the name of the actual compound measured. It can be seen that Nonorganic garlic had the least amount of volatiles present, whereas Elephant garlic had the most. These values may help to explain why the odor or taste of some garlic cultivars may be perceived as "strong" while others are perceived as "mild".

Fig. (3) shows the results of Principal Component Analysis on the garlic samples analyzed. "Facter 1" and "Facter 2" have been used in place of Principal Component 1 (PC-1) and Principal Component 2 (PC-2) [19] since "Principal Components" are in fact not single compounds but a mathematical relationship between all of the compounds in the samples analyzed [20]. Although a number of PC's can be calculated only two PC-1 and PC-2 were required to explain most of data variance. PC-1 and PC-2 accounted for $98 \%$ of the total variance (75\% for PC-1 and $23 \%$ for PC-2).

In the same fashion PCA has recently been used to separate six species of blueberries [21].

\section{CONCLUSION}

After sample preparation and analysis were optimized, known cultivars of garlic, and non-organically grown garlic were distinguished using Principal Component Analysis.

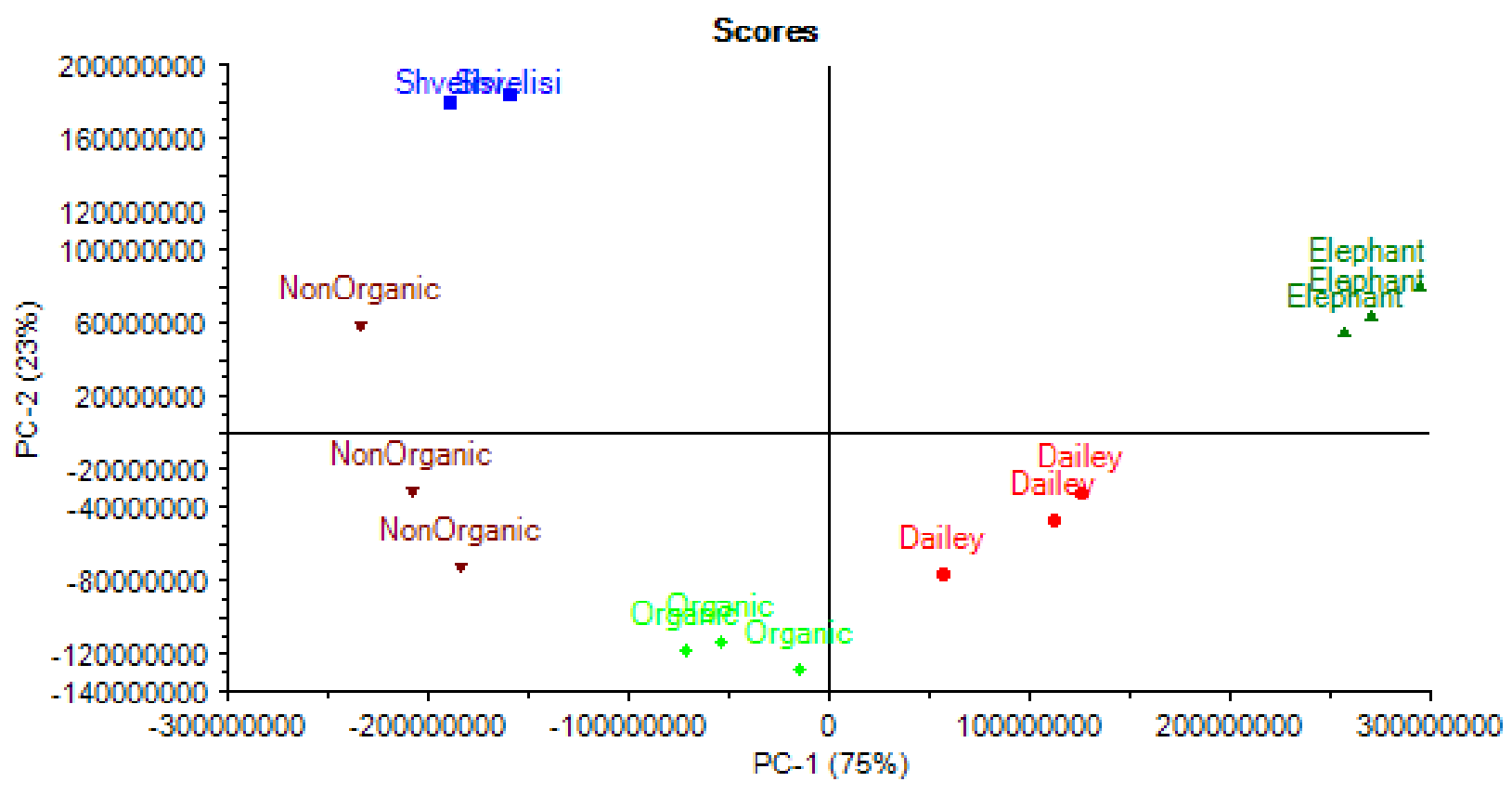

Shvelisi - Dailey $\quad$ Elephant $\quad$ Organic $\vee$ NonOrganic

Fig. (3). Principal component analysis (PCA) of garlic samples. 
Table 1. Relative Amounts ${ }^{\mathrm{b}}$ of Major Analytes in Garlic

\begin{tabular}{|c|c|c|c|c|c|}
\hline Compound $^{a}$ & Shvelisi & Dailey & Elephant & Organic & Nonorganic \\
\hline Allyl Methyl Sulfide & 47.5 & 42.7 & 214.2 & 9.1 & 5.7 \\
\hline Dimethyl Disulfide & 9.7 & 4.9 & 48.5 & 2.3 & 2.6 \\
\hline Methyl 2-Propenyl Disulfide & 173.8 & 145.9 & 374.4 & 119.9 & 35.2 \\
\hline Diallyl Disulfide & 569.0 & $1,458.9$ & $1,434.1$ & 648.5 & 268.7 \\
\hline Allyl Trisulfide & 1.9 & 52.4 & 41.5 & 15.4 & 0.7 \\
\hline
\end{tabular}

${ }^{\mathrm{a} C o m p o u n d ~ i d e n t i f i c a t i o n ~ b a s e d ~ o n ~ m a s s ~ s p e c t r u m ~[22] ~ a n d ~ r e t e n t i o n ~ i n d e x ~ m a t c h i n g ~ t o ~ t h o s e ~ o f ~ c o m m e r c i a l l y ~ a v a i l a b l e ~ r e f e r e n c e ~ s a m p l e s ~ o r ~ l i t e r a t u r e ~ v a l u e s . ~}{ }^{b}$ Average of triplicate analysis expressed as the total ion abundance (TIC) for each compound $\left(\mathrm{x} 10^{6}\right)$ when $2.0 \mathrm{~g}$ of each garlic type was analyzed.

\section{REFERENCES}

[1] Mulrow C, Lawrence V, Ackermann R, et al. Garlic: effects on cardiovascular risks and disease, protective effects against cancer, and clinical adverse effects. Evid Rep Technol Assess (Summ) 2000; 20: 1-4.

[2] Khanum F, Anilakumar K, Viswanathan K. Anticarcinogenic Properties of Garlic: A Review. Crit Rev in Food Sci Nutr 2004; 44: 479-88.

[3] Mukherjee S, Lekli I, Goswami S, Das D. Freshly crushed garlic is a superior cardio-protective agent than processed garlic. J Agric Food Chem 2009; 57: 7137-44.

[4] Thomson M, Ali M. Garlic [Allium sativum]: A review of its potential use as an anti-cancer agent. Current Cancer Drug Target 2003; 3: 67-81.

[5] Lawson L, Gardner C. Composition, stability, and bioavailability of garlic products used in a clinical trial. J Agric Food Chem 2005; 53: 6254-61.

[6] Yu T, Wu C, Liou Y. Volatile compounds from garlic. J Agric Food Chem 1989; 37: 725-30.

[7] Saghir A, Mann L, Bernhard R, Jacobsen J. Determination of aliphatic mono- and disulfides in allium by gas chromatography and their distribution in the common food species. Am Soc Hortic Sci 1964; 84: 386-98.

[8] Mochizuki E, Yamamoto T. Identification of allium products using flame photometric detection gas chromatography and distribution patterns of volatile sulfur compounds. J Agric Food Chem 1998; 46: 5170-6.

[9] Volk G, Henk A, Richards C. Genetic Diversity among U.S. Garlic Clones as Detected Using AFLP Methods. J Am Hortic Sci 2004; 129(4): 559-69

[10] Smith R. Determination of the country of origin of garlic (Allium sativum) using trace metal profiling. J Agric Food Chem 2005; 53: 4041-5.

[11] Dittmann B, Zimmermann B, Engelen C, Jany G, Nitz S. Use of the MS-Sensor to discriminate between different dosages of garlic flavoring in tomato sauce. J Agric Food Chem 2000; 48: 2887-92.
[12] Panthee D, KCR, Regmi H, Subedi P, Bhattarai S, Dhakal J. Diversity analysis of garlic (Allium sativum L.) gerplasms available in Nepal based on morphological characters. Genetic Res Crop Evol 2006; 53: 205-12.

[13] Block E, Naganathan S, Putman D, Zhao S. Allium Chemistry: HPLC Analysis of Thiosulfinates from Onion, Garlic, Wild Garlic (Ramsoms), Leek, Scallion, Shallot, Elephant (Great-Headed) Garlic, Chive, and Chinese Chive. Uniquely High Allyl to Methyl Ratios in Some Garlic Samples. J Agric Food Chem 1992; 40: 241830.

[14] Yu T, Wu C, Ho C. Volatile compounds of deep-Oil fried, microwave-heated, and oven-baked garlic slices. J Agric Food Chem 1993; 41: 800-5.

[15] Marsili, R. SPME Comparison studies and what they reveal in flavor, fragrance and odor analysis; Marsili, R., Ed.; Marcel Dekker, Inc; New York, 2001; pp. 206-27

[16] Itakura Y, Ichikawa M, Mori Y, Okino R , Udayama M, Morita T. How to distinguish garlic from other Allium vegetables. J Nutr 2001; 131: 964S.

[17] Bicchi C, Drigo S, Rubiolo P. Influence of fibre coating in headspace solid-phase microextraction gas chromatographic analysis of aromatic and medicinal plants. J Chromatogr A 2000; 892: 469-85.

[18] Dietz C, Perez-CCorona T, Madrid-Albarran Y, Camara C. SPME for on-line volatile organo-selenium speciation. J Anal At Spectrom 2003; 18: 467-73.

[19] Mochizuki E, Yamamoto T, Komiyama Y, Nakazawa H. Identification of allium products using flame photometric detection gas chromatography and distribution patterns of volatile sulfur compounds. J Agric Food Chem 1998; 46: 5170-6

[20] Esbensen, Kim H, Multivariate Data Analysis in practice, $5^{\text {th }}$. ed.; CAMO Software; Woodbridge, N.J. 2010

[21] Dastmalchi K, Flores G, Petrova V, Pedraza-Penalosa P, Edward J, Kennelly EJ. Edible neotropical blueberries: antioxidant and compositional fingerprint analysis. J Agric Food Chem 2011; 59: 30206.

[22] NIST/EPA/NIH Mass Spectral Library, Scientific Instrument Services, Ringoes, NJ 2008.

\section{(c) Clemente et al.; Licensee Bentham Open.}

This is an open access article licensed under the terms of the Creative Commons Attribution Non-Commercial License (http://creativecommons.org/licenses/by-nc/3.0/) which permits unrestricted, non-commercial use, distribution and reproduction in any medium, provided the work is properly cited. 